\title{
Editors' Preface
}

The editorial board is delighted to present Volume 17 of the Cambridge Yearbook of European Legal Studies. An important aim of the Yearbook is to reflect upon the challenges facing Europe and the legal implications of responses to those challenges. Climate change is, of course, not a uniquely European problem. Nonetheless, as Scott's article demonstrates, it is important to have an appropriate normative framework through which to assign and understand the European Union's environmental responsibilities. Likewise, the financial and economic crisis of the last decade reverberated not just across Europe but around the globe. Within the EU, it posed a particular challenge to the stability of economic and monetary union and the operation of the internal market in banking and financial services. Fabbrini's article highlights how the EU's response to the crisis has changed power relationships between Member States and the implications this has for the EU's constitutional order. For Chiti, what is also changing as a result of the crisis is the nature and role of EU administrative structures and agencies. Meanwhile, unilateral rather coordinated regulatory responses to global issues can create tensions in relations between the EU and other countries including the US, leading Jančić to call for heightened inter-parliamentary cooperation.

A useful way of thinking about 'European Legal Studies' is to explore the complex interactions between legal sources at European and national levels. A classic expression of this in European law is the study of EU harmonisation policy and Klamert's contribution urges greater clarity in how we think and talk about 'harmonisation'. The contributions by Mulheron (class actions) and Shaw (immigration) show how illuminating it can also be to start with the domestic legal context and then consider the mechanisms for, and impediments to, 'Europeanisation'.

Issues relating to legal sources are foregrounded in the analyses by Odermatt and Miettenen \& Kettunen in their studies of the legal resources available to the European Court of Justice in its adjudication. Vaughan's enquiry is directed less towards the legal sources used by courts and more towards the effects of apparently non-binding guidance authored by European agencies. Our thinking about binding and non-binding legal sources has been influenced by conceptual frameworks of 'legalisation'. Cardwell's article draws on these frameworks to investigate changes in EU foreign policy, not least the effects of EU foreign policy instruments on non-EU countries within the European region.

The protection of fundamental rights continues to be a significant source of legal controversy. Substantively, the interaction between employment rights and Charterprotected business freedoms is the subject of Prassl's analysis. For Storgaard and for Pirker \& Reitemeyer, the challenges posed are also conceptual and institutional, with the landmark Opinion 2/13 of the Court of Justice on EU accession to the ECHR casting a long shadow over future developments. 
Keeping pace with legal change is vital to the success of any legal journal. To secure the Yearbook's capacity to join, and influence, the conversation about the challenges facing Europe, we are delighted to be publishing through Cambridge Journals Online for the first time. The editors are extremely grateful to Rebecca O'Rourke for leading the Yearbook through its transition to CJO and to Sally Thomas and Sue Tuck for their incredible professionalism in producing this year's volume. The Yearbook is the principal publication of the Centre for European Legal Studies at the University of Cambridge and the editors also wish to express their gratitude to all who support the activities of CELS, not least the professional support provided by Felicity Eves-Rey.

As editors, it is vitally important to us that we develop strong working relationships with our authors, with good communication and feedback, and timely online publication in advance of annual print publication. The Editor-in-Chief is always happy to discuss publication plans with potential authors and can be emailed at cyels@law.cam.ac.uk.

Cambridge September 2015 